\title{
The Effect of Smoking on Diagnostic Value of Serum Matrix Metalloproteinase-8 in Acute Coronary Syndrome
}

\author{
Laura Lahdentausta ${ }^{1 *}$, Timo Sorsa ${ }^{1,2}$, Pirkko J Pussinen ${ }^{1,2}$ and Erkki Pesonen ${ }^{3,4}$ \\ ${ }^{1}$ Institute of Dentistry, University of Helsinki, Finland \\ ${ }^{2}$ Department of Oral and Maxillofacial Diseases, Helsinki University Central Hospital, Helsinki, Finland \\ ${ }^{3}$ Skåne University, Sweden \\ ${ }^{4}$ Department of Paediatrics, Division of Paediatric Cardiology, Skåne University Hospital, Lund, Sweden
}

\begin{abstract}
Background: Smoking has been perceived to increase the levels of carcinogenic and inflammatory mediators thereby promoting presumably malignant and proinflammatory tissue destruction via activating proteolytic enzymes such as matrix metalloproteinases (MMPs) and their regulators. We studied the effect of smoking on the diagnostic ability of serum MMP-8-IFMA and TIMP-1-ELISA analysis to recognize patients with acute coronary syndrome (ACS).

Methods: The case-control population $(n=605)$ comprised 291 patients with diagnosed acute myocardial infarction (AMI) or unstable angina pectoris (UAP) and 314 healthy control individuals. The case and the control group included 55 and 66 smoking subjects, respectively.

Results: Smoking increased the MMP-8, but not the TIMP-1, concentration in both the control and the AMI group. MMP-8 concentration, and consequently MMP-8/TIMP-1, distinguished the cases from the controls accurately in the ROC analysis, but smoking decreased the AUCs in every category. The MMP-8 concentration produced an AUC $(95 \% \mathrm{Cl}, \mathrm{p}$-value) for ACS of $0.771(0.723-0.818, p<0.001)$ and $0.684(0.581-0.787, p=0.001)$ for non-smokers and smokers, respectively. Similarly, the multivariate logistic regression model indicated that smoking decreased the association of MMP-8 with ACS. The OR $(95 \% \mathrm{Cl}$, p-value) of MMP-8 for ACS was 8.1 (per $\mathrm{ng} / \mathrm{ml}$ log-transformed unit increase, 5.0-13.1, $\mathrm{p}<0.001)$ and $2.8(1.1-7.0, p=0.025)$ for non-smokers and smokers, respectively.

Conclusions: One of the most important risk factors for ACS, smoking, decreases the diagnostic ability of MMP8 concentration and MMP-8/TIMP-1 ratio. This must be taken account if these serum determinations are used as biomarkers of the risk for cardiovascular diseases.
\end{abstract}

Keywords: MMP-8; TIMP-1; Acute coronary syndrome; Serum biomarker; Diagnostics; Smoking

\section{Introduction}

The atherosclerotic process is driven by a complex interplay of a multitude of risk factors through modulation of inflammatory, lipid, and immune mechanisms [1]. Smoking is perceived as a major cardiovascular risk factor along with diabetes, hypertension and hypercholesterolemia, being responsible for approximately $25 \%$ of cardiovascular deaths in USA and Europe [2]. Even environmental tobacco smoke exposure correlates with the magnitude of atherogenic changes in peripheral arteries [3]. Smoking has been regarded to diminish microcirculatory blood flow thereby reducing the oxygen availability in tissues leading to damage [4]. Furthermore, smoking has been considered to increase the amounts of inflammatory mediators such as reactive oxygen species, various cytokines and chemokines and proteolytic enzymes, such as matrix metallo proteinases (MMPs) and elastases in the affected tissues [5]. Thus by generating a circulus vitiosus of proinflammatory mediators, smoking can promote proinflammatory tissue destruction [6]. Smoking also intensifies the oxidative modification of low density lipoproteins (LDL), thereby increasing the atherogenic proinflammatory burden in the arterial wall [7].

MMPs form an enzyme superfamily of at least 23 genetically distinct but structurally related proteases [8]. The delicate balance between MMPs and tissue inhibitors of matrix metalloproteinases (TIMPs) regulates the degradation of extracellular matrix and basement membrane components [9]. Additionally MMPs process non-matrix bioactive substrates such as cytokines, chemokines, cell surface receptors and growth factors exerting potential to regulate immune and inflammatory responses [10]. Thus MMPs can act both surrogate by promoting protective tissue destruction or defensively providing anti-inflammatory shield [11].

Serum and plasma MMP-8 levels together with its major inhibitor TIMP-1 have been demonstrated to reflect disease severity and plaque instability in cardiovascular diseases (CVD) [12]. Our earlier study shows that MMP-8 and MMP-8/TIMP-1 concentrations are increased during ACS [13] and prevalent CVD as well as subclinical atherosclerosis [14]. High MMP-8 predicts all incident CVD events $[14,15]$, but associates especially with CVD death in men with subclinical atherosclerosis in a 10-year follow-up [14]. TIMP-1 concentration is an independent predictor of cardiovascular death in patients with prevalent CVD including coronary artery disease, chronic heart failure, or ACS $[13,16,17]$.

${ }^{*}$ Corresponding author: Laura Lahdentausta, Institute of Dentistry, University of Helsinki, Finland, E-mail: laura.lahdentausta@helsinki.fi

Received February 14, 2013; Accepted March 20, 2013; Published March 23 2013

Citation: Lahdentausta L, Sorsa T, Pussinen PJ, Pesonen E (2013) The Effect of Smoking on Diagnostic Value of Serum Matrix Metalloproteinase-8 in Acute Coronary Syndrome. J Mol Biomark Diagn S4: 002. doi:10.4172/2155-9929.S4002

Copyright: (C) 2013 Lahdentausta L, et al. This is an open-access article distributed under the terms of the Creative Commons Attribution License, which permits unrestricted use, distribution, and reproduction in any medium, provided the original author and source are credited 
Finding new biomarkers for fatal CVD events is highly important. MMP-8 may be regarded as such, and therefore exploring factors affecting its diagnostic ability is valuable. With this background we studied in case-control setting the effect of smoking on serum MMP-8 and TIMP-1 concentration in ACS.

\section{Methods}

\section{Subjects and diagnosis}

The inclusion criteria for the whole population $(n=605)$ were age under 80 years and no signs of cognitive intellectual disability. The participants completed a questionnaire on general background characteristics and demographic data. The study complies with the Declaration of Helsinki, and the ethical committee of the Lund University approved it. A written informed consent was obtained from the subjects.

Cases consisted of 291 patients, who were admitted for ACS to the heart intensive care unit in Lund University Hospital between March 1999 and April 2002 as described earlier in detail [13,18]. Acute myocardial infarction (AMI) was diagnosed in 197 individuals and unstable angina pectoris (UAP) in 94. AMI was diagnosed if two of the following criteria were fulfilled: i) typical chest pain lasting over $20 \mathrm{~min}$, ii) ST-elevations followed by $\mathrm{T}$-wave inversion or new $\mathrm{Q}$-waves in the ECG, or iii) an increase in CK-MB to more than twice the upper limit of the normal value. UAP was diagnosed in patients with i) continuous ischemic chest pain, ii) transient or persistent ST-segment depression in the ECG $(<1 \mathrm{~mm})$, and/or iii) elevation of CK-MB $(5<\mathrm{CK}-\mathrm{MB}<10$ $\mu \mathrm{g} / \mathrm{l})$ or troponin $\mathrm{T}(0.05<\mathrm{TNT}<0.10 \mu \mathrm{g} / \mathrm{l})$.

Control individuals $(\mathrm{n}=314)$ were chosen from the same area with the inclusion criteria: i) no history of definite or suspected coronary heart disease or stroke, ii) no operations or chemotherapy within the previous 4 weeks, iii) no medication for diabetes, hypertension, or dyslipidemia, iv) no history of angina i.e. chest pain in any location related to exercise and relieved by rest.

\section{Laboratory determinations}

Sera without clot activators were collected from the patients within 24 hours after the diagnosis. From the controls the samples were collected during the home visit made by the research nurse.
The laboratory determinations were done on frozen $\left(-20^{\circ} \mathrm{C}\right)$ samples. Serum MMP-8 concentrations were determined by a time-resolved immunofluorometric assay (IFMA) [14]. The inter-assay coefficient of variation $(\mathrm{CV})$ was $7.3 \%(\mathrm{n}=28)$ and detection limit for the assay $0.08 \mathrm{ng} / \mathrm{ml}$. TIMP-1-ELISA (R\&D Systems, Minneapolis MN, USA) was performed according to manufacturer's instructions. The interassay $\mathrm{CV} \%$ was $8.2 \%(\mathrm{n}=28)$ and the detection limit $0.08 \mathrm{ng} / \mathrm{ml}$. For calculations of MMP-8 / TIMP-1 molecular ratios, the concentrations were converted into moles using molecular weights of 65,000 and $28,000 \mathrm{~g} / \mathrm{mol}$ for MMP-8 and TIMP-1.

\section{Statistics}

In characteristics consisting of age, total cholesterol, LDL cholesterol, C-reactive protein (CRP), and blood pressure values were normally distributed and are presented as means with standard deviations (SD). MMP-8 and MMP-8/TIMP-1, which displayed skewed distributions, are presented as medians and inter quartile ranges (IQR). Statistical significance of the differences in these parameters according to smoking status was tested by using nonparametric Mann-Whitney test in each diagnose category. Statistical significance in categorical variables was tested by Chi-square test. Before determining the diagnostic sensitivity and specificity by receiving operating characteristics (ROC), MMP- 8 concentrations and MMP-8/ TIMP-1 ratios were log-transformed. C-statistics was produced from the predicted probabilities after adjusting for age and sex. Multivariate logistic regression models adjusted for age and sex were used when determining association of MMP-8 and MMP-8/TIMP-1 levels with ACS separately in smokers and non-smokers. The analyses were done using PASW Statistics version 18.0.

\section{Results}

The characteristics of the subjects are presented according to the smoking status in each diagnose class in table 1. The non-smokers were older compared to the smokers; the differences were statistically significant in the ACS groups. The CRP concentrations were higher in the smokers than in the non-smokers both in the control and the ACS groups.

Medians (IQR) of serum MMP-8 concentration and MMP-8/ TIMP-1 molar ratio in each diagnose category are presented in table

\begin{tabular}{|c|c|c|c|c|c|c|c|c|}
\hline & \multicolumn{2}{|c|}{ Controls } & \multicolumn{6}{|c|}{ Cases } \\
\hline & $\begin{array}{l}\text { Non- smoking } \\
\text { controls }(n=248)\end{array}$ & $\begin{array}{c}\text { Smoking } \\
\text { controls }(n=66)\end{array}$ & $\begin{array}{l}\text { Non-smoking } \\
\text { ACS }(n=236)\end{array}$ & $\begin{array}{c}\text { Smoking } \\
\text { ACS }(n=55)\end{array}$ & $\begin{array}{l}\text { Non-smoking } \\
\text { AMI }(n=152)\end{array}$ & $\begin{array}{c}\text { Smoking } \\
\text { AMI }(n=45)\end{array}$ & $\begin{array}{l}\text { Non-smoking } \\
\text { UAP }(n=84)\end{array}$ & $\begin{array}{l}\text { Smoking } \\
\text { UAP }(n=10)\end{array}$ \\
\hline \multicolumn{9}{|l|}{ Mean (SD) } \\
\hline Age (years) & $63.4(9.57)$ & $61.9(8.25)$ & $64.2(8.33)$ & $56.8(9.38) \ddagger$ & $64.6(8.06)$ & $56.9(9.31)$ * & $63.3(8.78)$ & $56.3(10.19)$ * \\
\hline Cholesterol (mmol/l) & $5.77(1.04)$ & $5.78(1.12)$ & $5.34(1.30)$ & $5.18(1.15)$ & $5.35(1.12)$ & $5.20(1.20)$ & $5.32(1.64)$ & $5.06(0.78)$ \\
\hline LDL cholesterol (mmol/l) & $3.69(1.05)$ & $3.74(1.13)$ & $3.40(1.05)$ & $3.10(1.11)$ & $3.50(1.09)$ & $3.15(1.14)$ & $3.13(0.88)$ & $2.70(0.85)$ \\
\hline $\mathrm{CRP}(\mathrm{mg} / \mathrm{l})$ & $2.08(2.08)$ & $2.96(2.91)^{*}$ & $20.8(33.5)$ & $39.7(61.3)$ * & $25.8(37.4)$ & $46.9(64.9)$ & $11.9(22.7)$ & $3.80(1.88)$ \\
\hline $\begin{array}{l}\text { Systolic blood pressure } \\
(\mathrm{mmHg})\end{array}$ & - & - & $140.7(19.8)$ & $134.3(21.7)$ & $140.9(21.4)$ & $132.9(22.5)$ & $140.4(17.2)$ & $143.3(15.3)$ \\
\hline $\begin{array}{l}\text { Diastolic blood pressure } \\
(\mathrm{mmHg})\end{array}$ & - & - & $79.5(11.4)$ & $82.1(12.8)$ & $79.9(12.1)$ & $81.3(13.5)$ & $78.9(10.3)$ & $86.7(5.77)$ \\
\hline \multicolumn{9}{|l|}{ n (\%) } \\
\hline Sex (\% men) & $196(79.0)$ & $50(75.8)$ & $186(78.8)$ & $45(81.8)$ & $118(77.6)$ & $35(77.8)$ & $68(81.0)$ & $10(100.0)$ \\
\hline Diabetic & - & - & $30(13.2)$ & $7(13.0)$ & $20(13.6)$ & $6(13.6)$ & $10(12.3)$ & $1(10.0)$ \\
\hline "Lipid lowering"-medicated & - & - & & & $23(15.1)$ & $8(17.8)$ & $32(40.5)$ & $6(60)$ \\
\hline
\end{tabular}

${ }^{*} p<0.05, \dagger p<0.01, \ddagger p<0.001$ compared to the corresponding non-smoking category using the Mann-Whitney test for continuous variables and Chi-square test for categorical variables

Table 1: Characteristics of the subjects according to the smoking status. 
Citation: Lahdentausta L, Sorsa T, Pussinen PJ, Pesonen E (2013) The Effect of Smoking on Diagnostic Value of Serum Matrix Metalloproteinase-8 in Acute Coronary Syndrome. J Mol Biomark Diagn S4: 002. doi:10.4172/2155-9929.S4-002

2. The smoking control subjects and the AMI patients had higher MMP-8 and MMP-8/TIMP-1 levels compared to the non-smoking subjects. The diagnostic ability of these determinations to distinguish the cases from the controls was analysed by the ROC separately for the smokers and non-smokers (Table 3). The AUCs were clearly higher in all comparisons for the non-smokers compared to the smokers. The diagnostic ability was further tested by $\mathrm{C}$-statistics adjusted for age and sex and comparable results were obtained (Figures 1A and 1B).

Finally, the associations of MMP-8 concentration and MMP8/TIMP-1 ratio with ACS were calculated by multivariate logistic regression models separately for the smokers and the non-smokers (Table 4). The associations of both of these determinations were stronger in the non-smoking than in the smoking population.

\section{Discussion}

In the present study we found that smoking significantly increases the serum MMP-8 concentration in generally healthy subjects and in patients with AMI, thereby jeopardizing its use as a diagnostic tool in ACS. Both the AUCs in C-statistics and the ORs in multivariate logistic regression models for ACS were lower in the smoking subjects compared to the non-smoking population. In contrary, smoking did not have an effect on the TIMP-1 concentration. In our earlier study with the same population, we showed that serum MMP-8 concentration, and consequently its molar ratio with TIMP-1, increased significantly

\begin{tabular}{|c|c|c|}
\hline Group & MMP-8 (ng/ml) & MMP-8/TIMP-1 \\
\hline \multicolumn{3}{|c|}{ Median (IQR) } \\
\hline \multicolumn{3}{|c|}{ Acute coronary syndrome } \\
\hline Non-smokers & $117.1(154.7)$ & $0.34(0.42)$ \\
\hline Smokers & $109.5(213.6)$ & $0.39(0.84)$ \\
\hline \multicolumn{3}{|c|}{ Unstable angina } \\
\hline Non-smokers & $91.0(137.4)$ & $0.32(0.45)$ \\
\hline Smokers & $52.1(44.5) *$ \\
\hline & Myocardial infraction \\
\hline Non-smokers & $121.3(147.1)$ & $0.16(0.20) *$ \\
\hline Smokers & $143.6(284.4)$ & $0.43(0.97) \ddagger$ \\
\hline & Controls \\
\hline Non-smokers & $41.3(61.2)$ & $0.14(0.21)$ \\
\hline Smokers & $71.7(92.0) \ddagger$ & $0.25(0.33) \ddagger$ \\
\hline
\end{tabular}

${ }^{*} p<0.05, \dagger p<0.01, \ddagger p<0.001$ compared to the corresponding non-smoking category by Mann-Whitney test

Table 2: Median serum MMP-8 concentrations and MMP-8/TIMP-1 ratios according to the smoking status.

\begin{tabular}{|c|c|c|}
\hline Group & MMP-8 (ng/ml) & MMP-8/TIMP-1 \\
\hline \multicolumn{4}{|c|}{ Area under the curve (95\% CI), p } \\
\hline \multicolumn{4}{|c|}{ Acute coronary syndrome } \\
\hline All & $0.729(0.692-0.767),<0.001$ & $0.707(0.668-0.746),<0.001$ \\
\hline Non-smokers & $0.750(0.707-0.793),<0.001$ & $0.732(0.688-0.777),<0.001$ \\
\hline Smokers & $0.620(0.518-0.721), 0.024$ & $0.621(0.520-0.722), \quad 0.022$ \\
\hline & \multicolumn{2}{|c|}{ Unstable angina } \\
\hline All & $0.668(0.610-0.726),<0.001$ & $0.660(0.602-0.719),<0.001$ \\
\hline Non-smokers & $0.714(0.652-0.776),<0.001$ & $0.707(0.643-0.771),<0.001$ \\
\hline Smokers & $0.330(0.170-0.490), 0.085$ & $0.341(0.179-0.503), 0.107$ \\
\hline & Myocardial infraction \\
\hline All & $0.757(0.718-0.797),<0.001$ & $0.729(0.686-0.770),<0.001$ \\
\hline Non-smokers & $0.771(0.723-0.818),<0.001$ & $0.746(0.696-0.795),<0.001$ \\
\hline Smokers & $0.684(0.581-0.787), 0.001$ & $0.684(0.582-0.786), 0.001$ \\
\hline
\end{tabular}

Table 3: ROC data of serum MMP-8 concentrations and MMP-8/TIMP-1 ratio for ACS according to the smoking status.

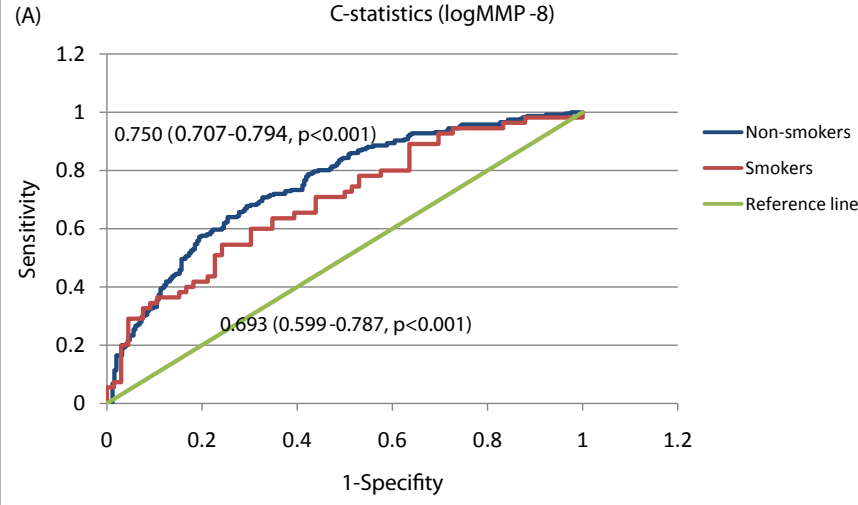

(B) C-statistics (logMMP-8/TIMP -1)

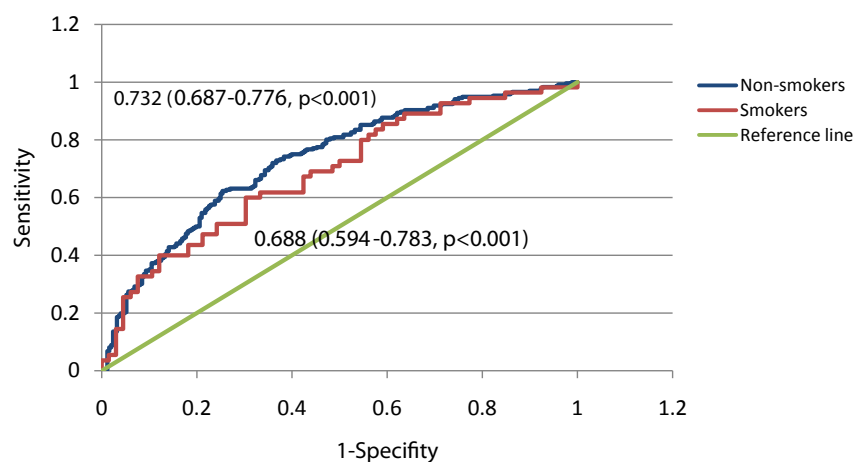

Figure 1: A and 1B: C-statistics of MMP-8 level and MMP-8/TIMP-1 ratio for ACS separately for smoking and non-smoking subjects. Serum MMP8 and TIMP-1 concentrations were determined in a case-control sample $(n=605)$. The molar ratio of MMP- 8 and TIMP- 1 was calculated and the MMP-8 concentrations were log-transformed. ROC analyses for ACS were performed using predicted probabilities produced by logistic regression models adjusted for age and sex. AUC, $95 \% \mathrm{Cl}$, and $\mathrm{p}$-values are presented in the figures shown for A) MMP-8 levels and B) MMP-8/TIMP-1 ratio.

\begin{tabular}{|c|c|c|c|c|}
\hline \multicolumn{5}{|c|}{ Oddsratio $(95 \% \mathrm{Cl})$} \\
\hline Group & logMMP-8 & $p$ value & logMMP-8/TIMP-1 & p value \\
\hline \multicolumn{5}{|c|}{ Acute coronary syndrome } \\
\hline All & $6.74(4.51-10.1)$ & $<0.001$ & $4.97(3.42-7.23)$ & $<0.001$ \\
\hline Non-smokers & $8.06(4.95-13.1)$ & $<0.001$ & $6.08(3.87-9.56)$ & $<0.001$ \\
\hline Smokers & $2.83(1.14-7.00)$ & 0.025 & $2.35(0.98-5.64)$ & 0.056 \\
\hline \multicolumn{5}{|c|}{ Unstable angina } \\
\hline All & $3.73(2.24-6.21)$ & $<0.001$ & $3.22(1.98-5.25)$ & $<0.001$ \\
\hline Non-smokers & $5.35(2.93-9.77)$ & $<0.001$ & $4.72(2.65-8.40)$ & $<0.001$ \\
\hline Smokers & No determined & & No determined & \\
\hline \multicolumn{5}{|c|}{ Myocardial infraction } \\
\hline All & $9.00(5.64-14.4)$ & $<0.001$ & $6.18(4.02-9.49)$ & $<0.001$ \\
\hline Non-smokers & $9.63(5.45-17.0)$ & $<0.001$ & $6.94(4.10-11.7)$ & $<0.001$ \\
\hline Smokers & $6.77(2.24-20.5)$ & 0.001 & $5.46(1.91-15.6)$ & 0.002 \\
\hline
\end{tabular}

Table 4: Associations of serum MMP-8 concentrations and MMP-8/TIMP-1 ratios with ACS according to the smoking status.

in ACS; the increment was 2.5- and 2.1-fold compared to the healthy controls [13]. Furthermore, high TIMP-1 concentration, which was not associated with prevalent ACS, predicted ACS recurrence and CVD death in the follow-up [13]. Therefore, these determinations could be regarded as useful markers for ACS, and the factors affecting their diagnostic ability need to be explored. 
Also known as collagenase-2 or neutrophil collagenase, MMP8 belongs to collagenase subgroup of MMPs [19]. MMP-8 can be expressed by a wide variety of cells including neutrophils, macrophages, plasma cells, T-cells, endothelial cells and fibroblasts. Regarding CVD, especially macrophage-associated MMP- 8 is increased at rupture sites of abdominal aorta $[20,21]$ which probably is reflected in the serum concentrations of the patients with arterial diseases [22]. Also in myocardial infarction the levels of MMP-8 are significantly elevated at the sites of affected tissue such as atheromas and carotid artery plaques [12,23]. Pathophysiologically, AMI and UAP have similar basic mechanisms; an ischemic attack of the heart muscle. However, a plaque rupture plays an essential role in the mechanism of AMI whereas its role is smaller or non-existent in some cases of UAP. High serum MMP-8 may be considered as a special marker of ACS with plaque rupture in contrast to e.g. CRP, which non-specifically reflects the amount of myocardial cell destruction. Undoubtedly, the well-known inflammatory state caused by smoking [24] was seen in the present study: Especially high mean CRP concentrations were observed in smoking AMI patient category compared to their non-smoking counterparts ( 46.9 vs. $25.8 \mathrm{mg} / \mathrm{l}$ ), but a significant difference was also detected between the smoking and non-smoking controls. The CRP concentrations correlate strongly with the MMP-8 concentrations [25].

The smoking ACS patients had higher median MMP-8/TIMP-1 molar ratio compared to the non-smokers. Strangely, smoking UAP patients had significantly lower MMP-8 and MMP-8/TIMP-1 medians compared to non-smoking UAP patients. The low number of smoking UAP patients $(n=10)$ is the probable explanation for these findings; odds ratios were not possible to determine for smoking UAP patients because of the low number of the patient. Associations of serum MMP-8 concentrations and MMP-8/TIMP-1 ratios with ACS were substantially higher in the non-smoking population compared those smoking, and the same trend was seen in the AMI category.

In addition to smoking, several other factors have been implicated to influence serum MMP-8 concentrations. Persons with metabolic syndrome have higher MMP-8 levels even in absence of diabetes or CVD [26]. Furthermore, patients suffering from type 2 diabetes combined with CVD have higher MMP-8 levels compared to nondiabetic patients with CVD [27]. Statins reduce MMP-8 levels [28], thus interfering with the use of MMP-8 in the diagnostics of CVD. When the present patient population was collected, statins were not as widely used as nowadays.

Smoking can eventually disturb considerably the diagnostic value of serum MMP-8 analysis in CVD through several complicated and partly unknown mechanism. Eventually, it is also possible that smoking is such a strong risk factor that it diminishes other parameters in association studies. In conclusion, smoking can significantly disturb the usefulness of serum MMP-8 and MMP-8/TIMP-1 analysis as adjunctive diagnostic tool in CVD.

\section{Acknowledgements}

The study was financially supported by grants from the Sigrid Juselius Foundation, the Paulo Foundation and the Helsinki University Central Hospital Research Foundation (EVO).

\section{References}

1. Libby P, Ridker PM, Maseri A (2002) Inflammation and atherosclerosis. Circulation 105: 1135-1143.

2. Milei J, Grana DR (1998) Mortality and morbidity from smoking-induced cardiovascular diseases: the necessity of the cardiologist's involvement and commitment. Int J Cardiol 67: 95-109.
3. Celermajer DS, Sørensen KE, Georgakopoulos D, Bull C, Thomas O, et al (1993) Cigarette smoking is associated with dose-related and potentially reversible impairment of endothelium-dependent dilation in healthy young adults. Circulation 88: 2149-2155.

4. Lehr HA (2000) Microcirculatory dysfunction induced by cigarette smoking Microcirculation 7: 367-384

5. Nordskog BK, Blixt AD, Morgan WT, Fields WR, Hellmann GM (2003) Matrixdegrading and pro-inflammatory changes in human vascular endothelial cells exposed to cigarette smoke condensate. Cardiovasc Toxicol 3: 101-117.

6. Arnson $\mathrm{Y}$, Shoenfeld $\mathrm{Y}$, Amital $\mathrm{H}$ (2010) Effects of tobacco smoke on immunity inflammation and autoimmunity. J Autoimmun 34: J258-265.

7. Fickl H, Van Antwerpen VL, Richards GA, Van der Westhuyzen DR, Davies $\mathrm{N}$, et al. (1996) Increased levels of autoantibodies to cardiolipin and oxidised low density lipoprotein are inversely associated with plasma vitamin $\mathrm{C}$ status in cigarette smokers. Atherosclerosis 124: 75-81

8. Klein T, Bischoff R (2011) Physiology and pathophysiology of matrix metalloproteases. Amino Acids 41: 271-290

9. Visse R, Nagase H (2003) Matrix metalloproteinases and tissue inhibitors of metalloproteinases: structure, function, and biochemistry. Circ Res 92: 827839.

10. Korpos E, Wu C, Sorokin L (2009) Multiple roles of the extracellular matrix in inflammation. Curr Pharm Des 15: 1349-1357.

11. Sorsa T, Tervahartiala T, Leppilahti J, Hernandez M, Gamonal J, et al. (2011) Collagenase-2 (MMP-8) as a point-of-care biomarker in periodontitis and cardiovascular diseases. Therapeutic response to non-antimicrobial properties of tetracyclines. Pharmacol Res 63: 108-113.

12. Turu MM, Krupinski J, Catena E, Rosell A, Montaner J, et al. (2006) Intraplaque MMP-8 levels are increased in asymptomatic patients with carotid plaque progression on ultrasound. Atherosclerosis 187: 161-169.

13. Pussinen PJ, Sarna S, Puolakkainen M, Öhlin H, Sorsa T, et al. (2012)The balance of serum matrix metalloproteinase- 8 and its tissue inhibitor in acute coronary syndrome and its recurrence. Int $\mathrm{J}$ Cardiol.

14. Tuomainen AM, Nyyssönen K, Laukkanen JA, Tervahartiala T, Tuomainen TP, et al. (2007) Serum matrix metalloproteinase-8concentrations are associated with cardiovascular outcome in men. Arterioscler Thromb Vasc Biol 27: 2722 2728.

15. Tuomainen AM, Kormi I, Havulinna AS, Tervahartiala T, Salomaa V, et al. (2012) Serum tissue-degrading proteinases and incident cardiovascular disease events. Eur J Prev Cardiol.

16. Lubos E, Schnabel R, Rupprecht HJ, Bickel C, Messow CM, et al. (2006) Prognostic value of tissue inhibitor of metalloproteinase-1 for cardiovascular death among patients with cardiovascular disease: results from the AtheroGene study. Eur Heart J 27: 150-156.

17. Frantz S, Störk S, Michels K, Eigenthaler M, Ertl G, et al. (2008) Tissue inhibitor of metalloproteinases levels in patients with chronic heart failure: an independent predictor of mortality. Eur J Heart Fail 10: 388-395.

18. Pesonen E, Andsberg E, Ohlin H, Puolakkainen M, Rautelin H, et al. (2007) Dual role of infections as risk factors for coronary heart disease. Atherosclerosis 192: $370-375$

19. Klein T, Bischoff R (2011) Physiology and pathophysiology of matrix metalloproteases. Amino Acids 41: 271-290.

20. Molloy KJ, Thompson MM, Jones JL, Schwalbe EC, Bell PR, et al. (2004) Unstable carotid plaques exhibit raised matrix metalloproteinase-8 activity Circulation 110: 337-343

21. Wilson WR, Schwalbe EC, Jones JL, Bell PR, Thompson MM (2005) Matrix metalloproteinase 8 (neutrophil collagenase) in the pathogenesis of abdominal aortic aneurysm. Br J Surg 92: 828-833.

22. Pradhan-Palikhe $P$, Vikatmaa $P$, Lajunen $T$, Palikhe $A$, Lepäntalo $M$, et al (2010) Elevated MMP-8 and decreased myeloperoxidase concentrations associate significantly with the risk for peripheral atherosclerosis disease and abdominal aortic aneurysm. Scand J Immunol 72: 150-157.

23. Herman MP, Sukhova GK, Libby P, Gerdes N, Tang N, et al. (2001) Expression of neutrophil collagenase (matrix metalloproteinase-8) in human atheroma: a novel collagenolytic pathway suggested by transcriptional profiling. Circulation 104: 1899-1904. 
Citation: Lahdentausta L, Sorsa T, Pussinen PJ, Pesonen E (2013) The Effect of Smoking on Diagnostic Value of Serum Matrix Metalloproteinase-8 in Acute Coronary Syndrome. J Mol Biomark Diagn S4: 002. doi:10.4172/2155-9929.S4-002

Page 5 of 5

24. Das I (1985) Raised C-reactive protein levels in serum from smokers. Clin Chim Acta 153: 9-13

25. Sorsa T, Tervahartiala T, Leppilahti J, Hernandez M, Gamonal J, et al. (2011) Collagenase-2 (MMP-8) as a point-of-care biomarker in periodontitis and cardiovascular diseases. Therapeutic response to non-antimicrobial properties of tetracyclines. Pharmacol Res 63: 108-113.

26. Kato R, Momiyama Y, Ohmori R, Taniguchi H, Nakamura H, et al. (2005) Plasma matrix metalloproteinase-8 concentrations are associated with the presence and severity of coronary artery disease. Circ J 69: 1035-1040.
27. Marx N, Froehlich J, Siam L, Ittner J, Wierse G, et al. (2003) Antidiabetic PPAR gamma-activator rosiglitazone reduces MMP-9 serum levels in type 2 diabetic patients with coronary artery disease. Arterioscler Thromb Vasc Biol 23: 283288.

28. Aquilante CL, Beitelshees AL, Zineh I (2007) Correlates of serum matrix metalloproteinase-8 (MMP-8) concentrations in nondiabetic subjects without cardiovascular disease. Clin Chim Acta 379: 48-52.
This article was originally published in a special issue, Protein \& Prognostic Biomarkers handled by Editor(s). Dr. David Zhang, Fudan University, USA; Dr. Wellington Pham, Vanderbilt University, USA; Jin-ichi Inokuchi, Tohoku Pharmaceutical University, Japan 